\title{
Assessing the sustainability of design and maintenance strategies for rail track by means of life cycle cost analysis
}

\author{
F. G. Praticò ${ }^{1} \&$ M. Giunta ${ }^{2}$ \\ ${ }^{1}$ DIIES Department University Mediterranea of Reggio Calabria, Italy \\ ${ }^{2}$ DICEAM Department University Mediterranea of Reggio Calabria, Italy
}

\begin{abstract}
According to the European vision for transport, the increase of train speed (especially for passenger traffic) and axle load, interoperability (technical compatibility of infrastructure, rolling stock, signalling and other subsystems of the rail system), and the increase of axle load are relevant goals to achieve in the future. The above goals interact with the following challenges: making infrastructure more reliable and resilient, keeping pace with the growing mobility requirements, reducing the impact of infrastructure on the environment (carbon footprint), maintaining and upgrade deteriorating transport infrastructures (renewal processes), applying innovative track design and materials. Ballast-less, slab track systems seem to be suitable to the aim, especially when high-speed passenger trains share the track with freight trains, although ballasted track is still widely used in high-speed lines. In light of the above, the study described in this paper aims at setting up a method for assessing the best strategy for the design and management of a railway track over time (maintenance and renewal), considering a long-term perspective and tangible and intangible costs. For both traditional ballasted and innovative slab tracks, life cycle costs are estimated based on agency (construction, inspection, maintenance and renewal), environmental $\left(\mathrm{CO}_{2}\right.$ emission), and user (delays-related etc.) present values. The trend of agency, user, and externality costs of the alternatives over the entire life cycle of the infrastructure allows recognizing the most sustainable solution. Results show that solutions that are reasonably priced in the short term can yield maintenance and renewal processes which are unfavourable or less sustainable in the long term. Furthermore, which may impact public opinion and overall judgment, the "distance" between the (total) present value of the ballasted or ballast-less options
\end{abstract}


becomes too small to yield sound conclusions in favour of the first versus the second solution.

Keywords: ballasted track, slab track, life cycle cost, sustainability.

\section{Introduction}

In the last decades, there is a worldwide trend towards increased pressures on the railway infrastructures through increases in axle loads and train speeds. The tracks are therefore subjected to a wide range of bearing and bending stresses in the rails, pads, fasteners, sleepers/slabs, ballast and subgrade due to: i) the static mass of the vehicles; ii) the dynamic actions, such as lateral centrifugal forces on curves, longitudinal acceleration and braking forces; iii) vertical inertial forces from the motion of the wheel-set and its suspension, vibrational forces induced from imperfections in the rail surface (corrugations, joints, welds, defects) and in the wheels (flats and shells); iv) the dynamic response of the track components to above actions (Tzanakakis [1]). The need to make the track suitable to withstand these stresses requires an accurate design and includes enhanced maintenance concepts for ballasted track, new or improved construction method for slab track (Esveld [2, 3], Gautier [4]). The ballast-less slab track systems seem to be suitable to the aim, especially in rail lines in which high-speed passenger trains share track with freight trains. Ballast-less track slab is a continuous slab of concrete in which the rails are usually supported directly on the upper surface by using resilient pad. This system represents the typical solution for bridges and tunnels due to the rigid support they provide. Slab track is commonly used also for light rail transit systems.

The slab track system has many advantages if compared with traditional ballasted track system. Among these: low maintenance cost (approximately 20$30 \%$ less), higher availability, increased service life (50-60 years), higher lateral stability, reduction of weight and height of the track, easier and more economic vegetation control (Esveld [2], Lichtberger [5] and Darr and Fiebig [6]). On the other side, weaknesses of slab are: higher construction cost, higher noise radiation, due to the uncoupling of the rail fastening and the lack of noise absorption of the ballast bed. Concrete slab track and rail pads dampen some noise frequencies but may reflect other frequencies and this should be addressed in the design and maintenance of slab track (Di Mino et al. [7]). The mitigation of noise and vibration increases the costs of the slab track construction significantly. Considering the advantages and disadvantages of each system the choice of the more effective system comes from an accurate and comprehensive LCC analysis, because of the long-lasting impact related to design. According to ISO 15686-5, LCC can be defined as "the cost of an asset or its part throughout its life cycle, while fulfilling the performance requirements".

LCC provides the theoretical concepts needed to balance short-term and longterm costs and performance and allows the economic assessment of the competing design alternatives considering all significant costs (tangible and intangible) over time (Esveld [3], Zoeteman [8] and Stalder [9]). 
In light of the above, given the complexity of goals and boundary conditions, the study described in this paper aims at setting up a method for assessing the best strategy for the design and management of a railway track over the time (maintenance and renewal), considering a long-term perspective and tangible and intangible costs.

\section{Method statement for LCC analysis}

The method setup in the present work aims at merging technical issues and environmental concerns in order to perform a comprehensive examination of the track alternatives (traditional and innovative) and find a suitable solution. To this purpose, LCC is applied to different track solutions in terms of three main components of total cost (TC): agency costs (ACs), user costs (UCs) and externality costs (EXCs) (see Praticò et al. [10]), as shown in equation (1):

$$
T C=A C_{s}+U C_{s}+E X C_{S}
$$

As for the agency costs, they can be split in initial costs $\mathrm{CC}_{\mathrm{S}}$ (e.g., construction cost) and running costs, namely the costs related to the operational period (e.g. costs for maintenance $\mathrm{MC}_{\mathrm{S}}$ and renewal $\mathrm{RNWC}_{\mathrm{S}}$, etc.):

$$
A C_{s}=C C_{s}+M C_{s}+R N W C_{s}
$$

User costs include the costs related to delays $\left(\mathrm{CD}_{\mathrm{s}}\right)$ originated by work zones of given length and duration (Praticò and Vaiana [11], Praticò et al. [12] and Walls and Smith [13]). Delays can be divided into two general categories: routine (experienced during normal operations, including crew changes, meets, passes, and civil speed restrictions) and irregular (including maintenance, accidents, and short-term speed restrictions based on track conditions) (see Lovett et al. [14]).

In the current study, this last type of delays has been considered. Therefore, user costs can be expressed as:

$$
U C_{s}=C D_{s}=C D_{M A}+C D_{R N W}
$$

where $\mathrm{CD}_{\mathrm{MA}}$ and $\mathrm{CD}_{\mathrm{RNW}}$ stand for costs for delays due to maintenance and renewal respectively. According to (Lovett et al. [14]), the cost of train delay per hour varies based on a variety of factors organized into five main categories: crew, cars, lading, locomotives, and fuel. Most of these factors are affected by train and commodity composition. In many contexts delay penalty costs are negotiated explicitly in the contracts between train operators and rail infrastructure owners. Note that there have been many attempts to quantify delay costs, which resulted in values ranging from $\$ 200$ to more than $\$ 1,000$ train-hour (Schafer and Barkan [15], Dingler et al. [16], Schlake et al. [17] and Lai and Barkan [18]). Assuming an average train composition, then crew, car, lading, and locomotive costs are approximately $\$ 950$ per train-hour (Lovett et al. [19]).

The externality costs (EXCs) refer to the environmental effects related to construction/maintenance/renewal and connected activities such as transportation, quarrying, landfill use, material production (cement, steel, rubber, etc.). The above 
processes impact on the environment in terms of climate change $\left(\mathrm{CO}_{2} \mathrm{e}\right)$, air quality $\left(\mathrm{SO}_{\mathrm{x}}, \mathrm{NO}_{\mathrm{x}}, \mathrm{CO}, \mathrm{VOC}, \mathrm{PM}\right.$, etc.), noise, water quality, soil quality, biodiversity, land take, quarries, landfills, and visual effects (Yin and Siriphong [20] and Parry and Timilsina [21]).

The carbon dioxide is one of several heat-trapping greenhouse gases (GHGs) emitted; hence a carbon dioxide equivalency (amount of $\mathrm{CO}_{2}$ that would have the same global warming potential GWP, when measured over a specified timescale generally, 100 years) is usually used to evaluate the environmental impacts of processes and activities. It should be noted that the $\mathrm{CO}_{2} \mathrm{e}$ figure of cementitious material can be considered around $950 \mathrm{~kg} \mathrm{CO}_{2}$ per tonne (Lee et al. [22]), while the $\mathrm{CO} 2 \mathrm{e}$ figure of asphalt concrete is about $60 \mathrm{~kg} \mathrm{CO}_{2}$ per tonne (Zwan [23]).

Milford and Allwood [24], investigated the $\mathrm{CO}_{2}$ impact of current (ballasted) and future (ballast-less) rail track systems. They observed that vehicle operations contribute approximately for the $70 \%$ of life cycle $\mathrm{CO}_{2}$ emissions, while construction, maintenance and disposal of infrastructure are responsible for nearly $20 \%$ of $\mathrm{CO}_{2}$ emissions, and the remaining $10 \%$ is attributed to vehicle manufacture, maintenance and disposal. Furthermore, the analysis carried out showed that for ballasted track configurations, tracks with concrete sleepers have the lowest $\mathrm{CO}_{2}$ impact, followed by steel, hardwood and softwood, while several rail track designs yielded a lower impact (up to a $40 \%$ reduction in $\mathrm{CO}_{2}$ impact).

The quantification of externality costs is a difficult task. However, under given hypotheses, this objective can be successfully pursued. In this work the assessment of externality costs has been accomplished by considering: i) the quantity of $\mathrm{CO}_{2}$ equivalent corresponding to a given process and material; ii) the cost of a ton of $\mathrm{CO}_{2}$; iii) the remaining factors associated to the process under consideration (quarrying, landfill, transportation-related emissions, etc.); iv) a method for the treatment of $\mathrm{CO}_{2}$ cost fluctuation (see below).

Based on the above considerations, different classes of externalities, $\mathrm{EX}_{\mathrm{kj}}$, are considered, where $\mathrm{j}$ refers to the $\mathrm{j}$-th impact (e.g., $\mathrm{CO}_{2}$ equivalent), while $\mathrm{k}$ stands for the $\mathrm{k}$-th activity (e.g., construction, $\mathrm{EX}_{0}$, successive $\mathrm{k}^{\text {th }}$ rehabilitation/ routine maintenance, $\mathrm{EX}_{\mathrm{k}}$, etc.). The cost of each externality can be estimated by means of the equation

$$
C E X_{k}=\sum_{j} Q_{k j} \cdot U P_{k j}
$$

where $\mathrm{Q}_{\mathrm{kj}}$ represents the quantification of the $\mathrm{j}$-th impact due to the k-th activity and $\mathrm{UP}_{\mathrm{kj}}$ stands for the related unit price.

In order to make all the costs comparable, i.e. to express them in equivalent currency units, the cash flows occurring during the analysed life span are discounted to a base year, in which the choice among competing alternatives is being made (i.e. construction year).

Discounting includes interest and inflation. If a real interest rate is applied, the annual inflation rate can be excluded (see Sugden and Williams [25]).

For agency costs, it results in 


$$
P V_{A C}=C C_{s}+\sum C_{M} \cdot R^{E_{M}}+\sum C_{R N W} \cdot R^{E_{R N W}}
$$

where $\mathrm{R}$ is the ratio between $(1+\mathrm{i})$ and $(1+\mathrm{r}), i$ is the inflation rate, $r$ is the interest rate, $C_{M}$ and $E_{M}$ (costs and expected time, respectively) refer to maintenance and $\mathrm{C}_{\mathrm{RNW}}$ and $\mathrm{E}_{\mathrm{RNW}}$ refer to renewal. Note that track maintenance scheduling (rail grinding, tamping, track stabilisation, ballast injection, etc.) can vary and therefore the related costs can be modelled as annual.

User costs PVs are expressed as follows:

$$
P V_{U C}=P V_{D}=\sum C_{D M} \cdot R^{E_{M}}+\sum C_{D R N W} \cdot R^{E_{R N W}}
$$

where $\mathrm{C}_{\mathrm{DM}}$ and $\mathrm{C}_{\mathrm{DRNW}}$ are user costs for the given track length and type, for the given cycle (element of the running total), based on the abovementioned literature and based on data gathered for the specific context of application.

$$
P V_{E X}=C E X_{0}+\sum_{k} C E X_{k} \cdot R^{E_{k}}
$$

where $\mathrm{CEX}_{0}$ refers to externality costs related to construction while $\mathrm{CEX}_{\mathrm{k}}$ takes into account the externality costs due to operation/maintenance/rehabilitation activities and processes. Regarding the externality costs, it should be noted that the quantification of the $\mathrm{CO}_{2}$ emissions is a well-established practice and to this purpose, an example is offered by the EUETS (European Union Emissions Trading System, see Sijm et al. [26]). Unfortunately, the fluctuation of the carbon price is a matter of fact. Due to this fact, in the analysis carried out in the present work, an indicator which refers to the most critical relationship between "internal" (agency costs and user costs) and "internalised" costs (externality costs) is derived (lowest ratio "internal-to-external") and applied to each solution in order to get a linear magnification/decrease of externality costs. The indicator has been defined as follows:

$$
v=\min _{i=1,2, k} \frac{P V_{A C i}+P V_{U C i}}{P V_{E X i}}
$$

where $\mathrm{i}=1,2, \ldots \mathrm{k}$ is the ith competing alternative.

Bearing in mind the indicator, the second step is to operate in this vector space of the internalised factors to get a linear magnification/deamplification:

$$
P V_{E X_{i}}^{\prime}=v \cdot P V_{E X_{i}}
$$

By considering the above linear application, the expression of TPV results as follows:

$$
T P V=P V_{A C}+P V_{U C}+P V_{E X}^{\prime}
$$

Starting from the estimate of the TPV for each considered track solution (ballasted/slab system), it is possible to evaluate the gain originated by one 
solution with respect to another one, assumed as control case. In the case of the present work the slab (s) solution has been compared with the ballasted one (b) as follows:

$$
G_{i}=T P V_{b}-T P V_{s}
$$

A positive value of gain indicates that the innovative slab solution (s) are better than the traditional ballasted solution (b).

The problem modelling discussed above is represented in Figure 1.

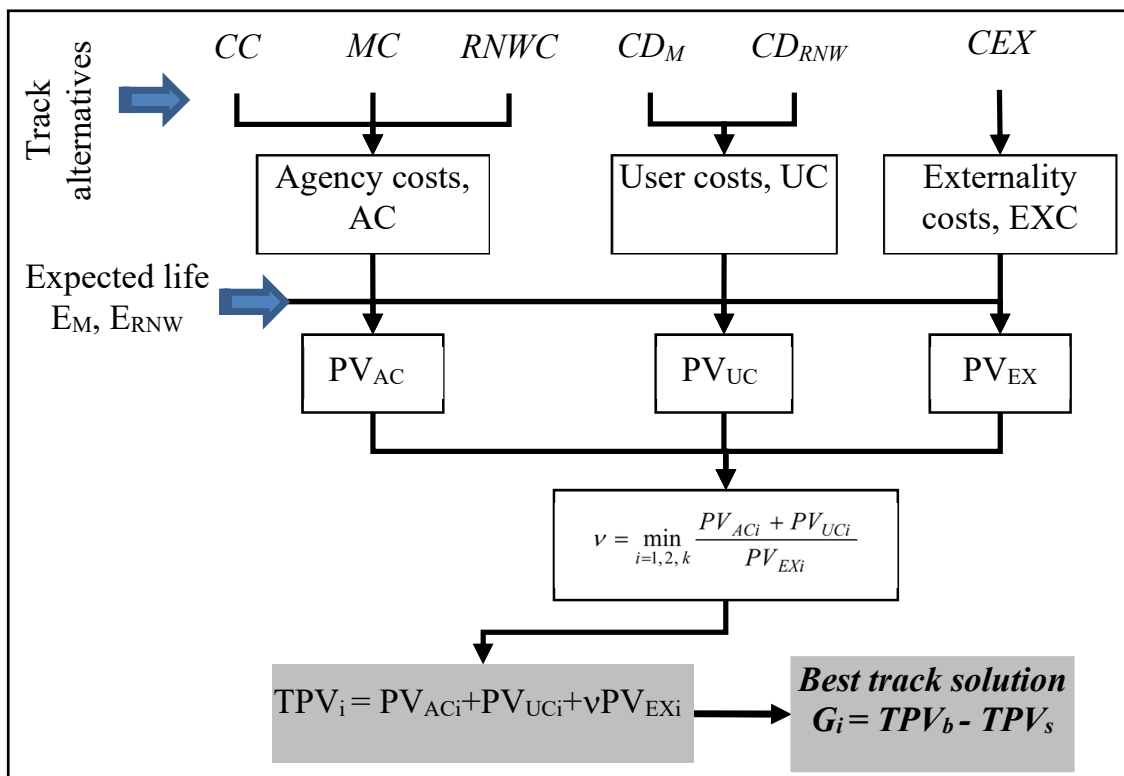

Symbols. CC: construction cost; MC: maintenance cost; RNWC: renewal cost; $\mathrm{C} D_{M}$ : delayrelated costs for maintenance; $D_{R N W}$ : delay-related costs for renewal; $E X_{k j}$ : externality cost which refers to the k-th activity/processes and j-th indicators: $\mathrm{CO} 2 \mathrm{e}, \mathrm{SOx}, \mathrm{NOx}, \mathrm{CO}, \mathrm{VOC}$, $\mathrm{PM} ; \mathrm{E}_{\mathrm{M}}, \mathrm{E}_{\mathrm{RNW}}$ : expected lives which refer to maintenance $(\mathrm{M})$ or renewal $(\mathrm{RNW})$; PV: present values, TPV: total present value; b: ballasted track, s: slab track; $\mathrm{G}=$ gains.

Figure 1: $\quad$ LCC modelling.

\section{Experiments and results discussion}

In the pursuit of the application of the above method for ballasted track, the main components considered are detailed below:

- Rail: type 60 E1 (UIC 60), $60 \mathrm{Kg} / \mathrm{ml}$, continuous welded rail.

- Sleepers: pre-stressed mono-block type RFI 260V- AV, length $2.60 \mathrm{~m}$, weight $325 \mathrm{Kg}$, distance between sleepers $0.669 \mathrm{~m}$, equipped with given baseplates. 
- Fastenings: elastic fastening type Vossloh W14 AV.

- $\quad$ Ballast: crushed stones, $500 \mathrm{~mm}$ (average depth).

- Subballast: cement treated layer, $200 \mathrm{~mm}$ depth.

The slab track system considered in this paper is the Japanese Shinkansen. It includes a sub-layer stabilized with cement (concrete road-bed), a cylindrical bollard to prevent lateral and longitudinal movements, and reinforced pre-stressed concrete slabs measuring $4.93 \mathrm{~m} \times 2.34 \mathrm{~m} \times 0.19 \mathrm{~m}$ and having a weight approximately of 5 tonnes (Esveld [3]). A double track line $1 \mathrm{Km}$-long has been considered.

The following tasks have been carried out to compare the two solutions:

- Task 1. Inventory of materials and construction-related processes.

- Task 2. Cost analysis and quantification (agency costs, user costs, externality costs).

- Task 3. Gains estimate.

As for Task, 1 a detailed analysis of the track components for each solution (rails, sleepers/concrete slabs, fastenings, baseplate, ballast/elastomeric pad, subballast/concrete base, embankment) and related production/construction processes has been performed.

Task 2 focused on the examination and quantification of costs, based on the analysis made during the Task 1 . As for construction, the related costs have been derived from data collected from Italian projects and literature in terms of planning and land cost, infrastructure building cost (tunnels, bridges, walls, crossings) superstructures costs (rails, sleepers, baseplates, fastenings), fixed equipment or electric traction (substation, catenary), signalling (cables, automatic, block system), stations, other costs.

Regarding the maintenance costs, it should be noted that typical maintenance activities are: rail grinding; replacement of defective rails and sleepers, tamping, track stabilisation, ballast injection. Frequencies, costs, methods can vary and approaches can be different. According to Baumgartner [27] and Silavong et al. [28] costs of maintenance activities mainly depend on speed and traffic and it is possible to consider the maintenance cost as running cost annually distributed. Based on literature and data gathered, in this study, the following formula for the annual maintenance cost (AMC, $\mathrm{k} €$, thousands of euros, per single track, per kilometre) has been set up:

$$
A M C=\left[2.2 \frac{(V-100)}{200}+4.00\right] \cdot G T K^{\left[-0.05 \frac{(V-100)}{200}+0,63\right]}
$$

where $\mathrm{V}[\mathrm{Km} / \mathrm{h}]$ is maximum speed allowed in the track and GTK refers to the traffic expressed as gross tonne kilometres [tonne $\cdot \mathrm{km}$ ]. Each maintenance operation corresponds to a given cost and a corresponding present value. As expected, annual maintenance cost for slab track resulted about $25 \%$ of the maintenance cost for ballasted track.

Regarding the externality costs, for each track component the amounts of $\mathrm{CO}_{2}$ released when making or using them were derived (Milford and Allwood [24], Leung [29]). The cost of a tonne of $\mathrm{CO}_{2}$ has been derived from Luckow et al. [30]. 
The user costs, estimated based on the delays caused by the maintenance and renewal activities, resulted lower (about a quarter) for slab track than for the ballasted track.

Task 3 focused on the estimation of the gain $(\mathrm{G})$ originated by one solution (for example, slab track) with respect to the control case (e.g., ballasted track). To this purpose, during this task, each option was associated to a given sum of present values (agency, user and externality costs). Note that the gain can be evaluated with consideration of only agency costs, or only externalities, or any other combinations as appropriate.

Results of the study are represented and summarised in figure 2, where total costs, agency costs, user costs and externality costs ( $\mathrm{y}$-axis) vary over time ( $\mathrm{x}$ axis), for the two considered options (ballasted track, b, versus slab track, s).

It can be observed that, despite the total costs at construction stage for slab tracks are higher than for ballasted solution (2.56 versus 1.65 million of euros), after twenty-seven years the slab solution exhibits a present value which is lower than the one yielded by the ballasted track. After about one century, the ballasted track yields an overall (internal) present value which is 1.1 times the one associated to the slab track.

A similar tendency can be observed for the agency costs. The agency costs for the slab track (1.2 times higher at construction stage), evolve slower than for the ballasted solution and after just sixteen years the breakeven point is reached $(\mathrm{PV} \mathrm{AC}$ are equal for $b$ and $s)$. In the successive years the agency costs of slab track remain about the $15 \%$ lower than the one of the ballasted track. Results confirm that agency costs cannot be analysed based only on construction cost, since solutions more suitable in short-term could become inconvenient in a long-term time frame.

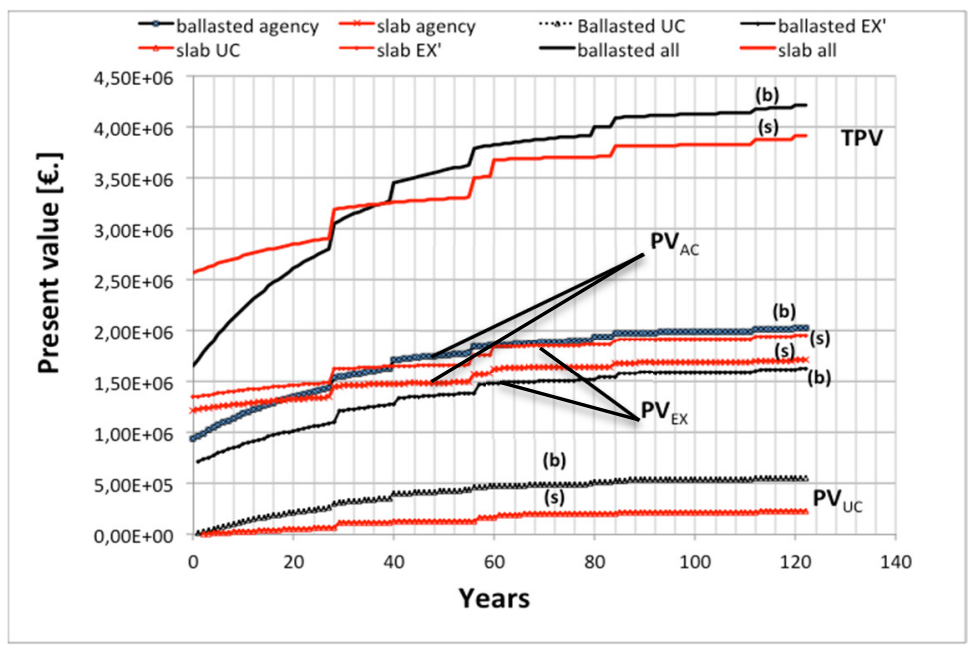

Figure 2: $\quad$ Trends of PVs over the time for ballasted (b) and slab (s) track. 
As for the present value of user costs, it appears consistent with literature (Esveld [3], Schilder and Diederich [31], Pichler and Fenske [32]). The basic elements which underlie the results, in terms of trend for the two solutions, are the following: i) maintenance and renewal processes affect long-term user costs due to the delays; ii) the maintenance process is slightly more expensive (in terms of frequencies and durations) for the ballasted track; iii) consequently, the PV of the user costs of the ballasted track solution is higher than the corresponding PV of the slab solution. Ballasted track yields a cost which is 2.3 times the one exhibited by the slab track after the same period of analysis (more than one century).

An opposite trend can be observed for the present value of the external costs over time. The slab solution yields higher (1.2 times) externality costs than the traditional slab track. This is due to carbon footprint associated to the production of cement. Form the environmental standpoint the traditional track system seems to be more preferable than the innovative solution.

\section{Conclusions}

The analysis carried out confirms that tangible and intangible costs govern the suitability of a track to fit transportation and environmental demand. Considering and integrating technical issues and environmental concerns is a difficult task, but it results the best way to make a comprehensive comparison among different design and maintenance track solutions.

In the present work, a model that encompasses technical requirements and environmental concerns has been formalised; it is founded on the analysis of the cost of the cycle of life of a ballasted or slab track. The following conclusions, therefore, can be drawn from the findings in this study.

1) As expected, present values increase over time even if their growth rate decrease over time.

2) In terms of agency costs (construction, maintenance and renewal) ballasted tracks yield a cost which is 1.15 times than the one exhibited by slab tracks after the same period of analysis (more than one century).

3) As for the user costs, ballasted track yields a cost which is 2.3 times the one exhibited by the slab track.

4) Environmental impact can make the difference. In more detail, cement carbon footprint is a key factor in the comparison. For the slab solution externality costs are 1.2 times higher than for the traditional slab track.

5) In a long-term and general perspective, the ballast-less solution results more suitable than the ballasted system. However, the "distance" between the (total) present value of the two solutions under analysis is too small to yield sound conclusions in favour of the ballasted versus the ballast-less solution. An in depth consideration on the type of track (rail freight corridor, high-speed track, regional tracks) could make the difference in terms of algorithm output and decision making.

The above results can benefit both researchers and practitioners. Future research will address how high speed and high capacity lines may perform in terms of the above classes of costs. 


\section{References}

[1] Tzanakakis K., The Railway Track and Its Long Term Behaviour. A Handbook for a Railway Track of High Quality, Volume 2 of the series 2013 Springer Tracts on Transportation and Traffic pp. 279-292.

[2] Esveld C., Slab track: A Competitive Solution, 1999.

[3] Esveld C., Modern Railway Track, Second Edition. Delft University of Technology 2001.

[4] Gautier, P.E., Slab track: Review of existing systems and optimization potentials including very high speed. Construction and Building Materials 92 (2015) pp. 9-15.

[5] Lichtberger B. Track compendium, First edition. Eurail Press 2005.

[6] Darr E. \& Fiebig W., Feste Fahrbahn: Konstrktion und Bauarten für Eisenbahn und Strassenbahn, Second edition. Eurailpress. Germany, 2006.

[7] Di Mino G., Giunta M. \& Di Liberto M.C., Assessing the open trenches in screening railway ground-borne vibrations by means of artificial neural network. Int. Journ. Advances on Acoustics and Vibration Vol. 2009, Article ID 942787, 12 pages ISSN: 1687-6261.

[8] Zoeteman, A., Life cycle cost analysis for managing rail infrastructure: Concept of a decision support system for railway design and maintenance EJTIR, 1, no. 4/2001, pp. 391-413.

[9] Stalder, O., The life cycle costs (LCC) of entire rail networks: An international comparison, Rail International, International Railway Congress Association, Vol. 32, No. 4, pp. 26-31, ISSN 0020-8442, 2001.

[10] Praticò F.G., Sireesh S. \& Puppala A. J., Comprehensive Life Cycle Cost Analysis for the Selection of Stabilization Alternatives for Better Performance of Low Volume Roads. U.S. Transportation Research Board, TRB, Transportation Research record No. 2204, vol. 2, 2011a. pp. 120 129.

[11] Praticò, F.G. \& Vaiana, R., Improving infrastructure sustainability in suburban and urban areas: Is porous asphalt the right answer? And how? WIT Transactions on the Built Environment 2012.

[12] Praticò, F.G., Vaiana, R., Giunta, M., Iuele, T. \& Moro, A., Recycling PEMs back to TLPAs: Is that possible notwithstanding RAP variability? Applied Mechanics and Materials 2013.

[13] Walls, J. \& Smith, M.R., Life-Cycle Cost Analysis in Pavement Design. FHWA report FHWA-SA-98-079. Federal Highway Administration. Washington, D.C., 1998.

[14] Lovett, A.H., Dick C.T., Ruppert, Jr. C.J. \& C.P.L. Barkan. Cost and delay of railroad timber and concrete crosstie maintenance and replacement. Transportation Research Record: Journal of the Transportation Research Board. Vol. 2476, 2015 pp. 37-44.

[15] Schafer, D.H. \& Barkan, C.P.L., A Prediction Model for Broken Rails and an Analysis of their Economic Impact. Proceedings of the American Railway Engineering and Maintenance-of-Way Association Annual Conference. Salt Lake City, UT, 2008. 
[16] Dingler, M.H., Lai, Y.-C. \& Barkan, C.P.L., Economics of Expanding Capacity on a Single Track Heavy Haul Railway Line. Proceedings of 11th International Heavy Haul Railway Conference 2011.

[17] Schlake, B.W., Barkan, C.P.L. \& Edwards, J.R., Train delay and economic impact of in-service failures of railroad rolling stock". Transportation Research Record: Journal of the Transportation Research Board, 2261, pp. 124-133, 2011.

[18] Lai, Y.C. \& Barkan, C.P.L., Enhanced Parametric Railway Capacity Evaluation Tool. Transportation Research Record: Journal of the Transportation Research Board, 2117(-1), pp. 33-40, 2009.

[19] Lovett, A.H., Dick C.T \& Barkan C.P.L., Determining Freight Train Delay Costs on Railroad Lines in North America. Proceedings of the International Association of Railway Operations Research (IAROR) 6th International Conference on Railway Operations Modelling and Analysis, Tokyo, Japan, March 2015.

[20] Yin Y., \& Siriphong L., Internalizing emission externality on road networks, Transportation Research Part D: Transport and Environment, volume 11, Issue 4, July 2006, pp. 292-301.

[21] Parry, I. W. H \& Timilsina, G. R., Pricing Externalities from Passenger Transportation in Mexico City, Policy Research Working Paper 5071, The World Bank, Development Research Group. Environment and Energy Team, September 2009.

[22] Lee, C.K., Lee, J.Y. \& Kim, Y.K., Comparison of environmental loads with rail track systems using simplified life cycle assessment (LCA). WIT Transactions on the Built Environment 101, pp. 367-372, 2008.

[23] Zwan, J. V., How to diminish the carbon footprint of asphalt roads. Proc. of Eurasphalt and Eurobitume Congress Istanbul 2012: http://www.eecongress2012.org/EEUSB/content/slides/JanvanderZwan.pd f.

[24] Milford R.L. \& Allwood, J.M, Assessing the $\mathrm{CO}_{2}$ impact of current and future rail track in the UK. Transportation Research Part D 15 (2010) pp. 61-72.

[25] Sugden, R. \& Williams, A.B., The principles of practical cost-benefit analysis. Oxford University Press, 1978.

[26] Sijm, J., Neuhoff, K., \& Chen, Y., CO2 cost pass through and windfall profits in the power sector, Climate Policy, Volume 6, Issue 1, 2006.

[27] Baumgartner, J.P., Prices and costs in the railway sector. École Polytechnique fédérale de Lausanne. Laboratoire d'Intermodalité de Transports et de Planification. 2001.

[28] Silavong, C., Guiraud, L. \& Brunel, J., Estimating the marginal cost of operation and maintenance for French railway network. Proc. ITEA Conference-Toulouse, France, 5-7 June, 2014.

[29] Leung S., Carbon dioxide $\left(\mathrm{CO}_{2}\right)$ emissions of concrete, Standing Committee on Concrete Technology SCCT Annual Concrete Seminar 27 February 2009. 
262 Computers in Railways XV: Railway Engineering Design and Operation

[30] Luckow P., Stanton E. A., Fields S., Biewald B., Jackson S., Fisher J. \& Wilson R., Carbon Dioxide Price Forecast, Synapse Energy Economics Inc. March 2015.

[31] Schilder, R. \& Diederich, D., Installation Quality of Slab Track - A Decisive Factor for Maintenance. 2007 RTR Special pp. 76-78.

[32] Pichler, D. \& Fenske, J., Ballastless track systems experiences gained in Austria and Germany. Proc. of AREMA Annual Conference September 29October 2 2013, Indiana Convention Center Indianapolis. 